\title{
Electronic and Thermodynamic Properties of a Derivative of Dithiophosphonates
}

\author{
Alpaslan BAYRAKDAR ${ }^{1}$
}

\begin{abstract}
In this work, thermodynamic properties (Heat capacity, Entropies, Enthalpy, Gibbs free and Thermal energy) and frontier (HOMO, LUMO) molecular orbitals of a derivative dithiophosphonates molecule which is $\left.\left.{ }^{+} \mathrm{HN}\left(\mathrm{C}_{2} \mathrm{H}_{5}\right)_{3}\right]\left[\mathrm{CH}_{3} \mathrm{CHOC}_{6} \mathrm{H}_{3}\left(\mathrm{CF}_{3}\right)_{2}\right)\left(\mathrm{CH}_{3} \mathrm{OC}_{6} \mathrm{H}_{4}\right) \mathrm{PS}_{2}{ }^{-}\right]$in the ground state were calculated by using the quantum chemical calculation method such as density functional theory (DFT) employing B3LYP and HF levels with the 6-31G(d) basis set. In addition, the frontier molecular orbitals analysis of the molecule were researched using computational methods. Properties about the charge density distribution of the title compound and its chemical reactivity has been investigated with mapping molecular electrostatic potential surface.
\end{abstract}

Keywords: DFT, dithiophosphonates, HF, homo, lumo

\section{Ditiyofosfatların Bir Türevinin Elektronik ve Termodinamik Özellikleri}

ÖZET: $\mathrm{Bu}$ çalışmada, ditiyofosfat moleküllerinin bir türevi olan $\left.\left[{ }^{+} \mathrm{HN}\left(\mathrm{C}_{2} \mathrm{H}_{5}\right)_{3}\right]\left[\mathrm{CH}_{3} \mathrm{CHOC}_{6} \mathrm{H}_{3}\left(\mathrm{CF}_{3}\right)_{2}\right)\left(\mathrm{CH}_{3} \mathrm{OC}_{6} \mathrm{H}_{4}\right) \mathrm{PS}_{2}{ }^{-}\right]$molekülünün taban durumu termodinamik özellikleri (Isı kapasitesi, Entropi, Entalpi Gibbs ve Thermal enerji) ve öncü moleküler orbitalleri kuantum kimyasal hesaplama tekniklerinden olan yoğunluk fonksiyonel teorisi (DFT) B3LYP ve Hartree-Fock (HF) metodlarıyla, 6-31G(d) baz seti kullanılarak incelenmiştir. Bunlara ek olarak bileşiğin öncü moleküler orbitalleri analiz edilmiştir. Bileşiğe ait elektrostatik potansiyel yüzey haritası kullanılarak, bileşiğin aktivitesi ve yük yoğunluğu incelenmiştir.

Anahtar kelimeler: DFT, ditiyofosfat, HF, homo, lumo

\footnotetext{
${ }^{1}$ Alpaslan BAYRAKDAR (Orcid ID: 0000-0001-7967-2245), Asmalıevler mahallesi, Denizli, Türkiye 


\section{INTRODUCTION}

Dithiophosphonate and derivative molecules are widely used in agriculture and industry. For example, they are used to combat weeds in agriculture and to prevent oxidation of motor oils in industry. Therefore, in recent years, studies for the synthesis of dithiophosphonate and its different derivatives have increased considerably (Solak, 2011). A series of diethylphosphonate derivatized molecules have been synthesized by investigators In the last thirty years (Aragoni et al., 2000; Aragoni et al., 2001; Thomas et al., 2001; van Zyl et al., 2002; Gray et al., 2003; Maspero et al., 2003; Gray et al., 2004; Alberti et al., 2007; Gataulina et al., 2008; Liu et al., 2010; Karakus, 2011; Karakus et al., 2011; Aydemir et al., 2015; ASIF, 2018; Karakus et al., 2018). In some of our prior works (Karakus et al., 2004; Karakus, 2011; Karakus et al., 2011; Karakus et al., 2014), we have synthesized dithiophosphonates and their derivatives and then examined their properties. A derivative of dithiophosphonates compound which is $\left[{ }^{+} \mathrm{HN}\left(\mathrm{C}_{2} \mathrm{H}_{5}\right)_{3}\right]\left[\mathrm{CH}_{3} \mathrm{CHOC}_{6} \mathrm{H}_{3}\left(\mathrm{CF}_{3}\right)_{2}\right)\left(\mathrm{CH}_{3} \mathrm{OC}_{6} \mathrm{H}_{4}\right.$ $\left.\mathrm{PS}_{2}{ }^{-}\right]$was synthesized in the presence of the 2,4-Bis(4-methoxyphenyl)-1,3,2,4-

dithiadiphosphetane-2,4-disulfide and (R)-1[3,5-Bis(trifloromethyl)phenyl]ethanol in toluene reaction. The spectroscopic techniques such as IR, ${ }^{1} \mathrm{H},{ }^{13} \mathrm{C},{ }^{31} \mathrm{P}$ NMR and structural examination techniques such as X-ray crystallography were used to characterize the compound in our previous study. The available paper is a progress of our previous studies on dithiophosphonates derivates (Karakus et al., 2014).

Both experimental and theoretical studies on the constructional features of dithiophosphonates are seldom found in literature. For interpret experimental work, there is a need for theoretical studies on the electronic and thermodynamic properties of the molecule. Ab initio calculation technique of quantum chemical calculation methods is widely used in studying both physical and chemical properties of molecules (Chermette, 1998; Corminboeuf et al., 2006; Karabacak et al., 2008; Sundaraganesan et al., 2008a; Sundaraganesan et al., 2008b; Bayrakdar et al., 2015; Şener et al., 2017).

In this paper, thermodynamic properties and frontier molecular orbitals of the molecules were theoretically calculated for the title compound. The charge density dispertion and chemical reactivity of said title compound were investigated by means of molecular electrostatic potential surface mapping.

The article is arranged as follows; computational details are given in Part 2. Thermodynamic analysis and electronic simulation results for the compound considered in this paper are given and debated in Part 3. Finally, the evaluation of the obtained data is given in the last section.

\section{MATERIAL AND METHODS}

\section{Computational details}

In this paper, the atomic coordinates of the structure obtained from the X-ray analysis (Karakus et al., 2014) are used as the initial to determine the ground state structure of the molecule. In order to get complete information regarding to the electronic structure properties such as Highest Occupied Molecular Orbital (HOMO) and Lowest Unoccupied Molecular Orbital (LUMO) energy levels and Molecular Electrostatic Potential surface (MEPs) calculations to be studied in this work we have carried out quantum chemical computation in the frameworks of the Density Functional Theory (DFT/B3LYP) and Hatree-Fock (HF) methods by utilizing 6-31G(d) basis set. The Gaussian 09 package program (Foresman;Frish, 1996; Frisch et al., 2009) is used for theoretical 
studies. DFT method which contains hybrid functions have been generally preferred because of they are express and highly accurate calculation techniques for theoretical calculations.

Molecular structure has been optimizedin order to achieve most stable conformation of the molecule at the level of ab initio methods both DFT/B3LYP and HF levels, using the basis set of $6-31 \mathrm{G}(\mathrm{d})$ with considering C1-symmetry group. The ground satate structure scheme of our title molecule is given in Figure 1.

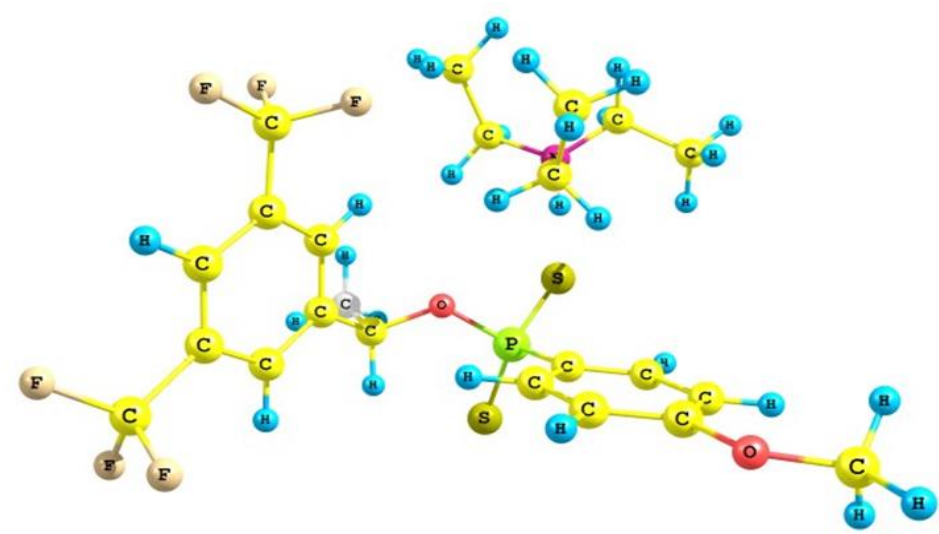

Figure 1. Optimized geometry of the title molecule with B3LYP/6-31G(d) level.

Analysis of the frontier molecular orbitals (HOMO-LUMO) provides us with a powerful way to understand the transfer of charge between levels of molecular energy of the molecule. HOMO and LUMO energy levels are calculated by DFT/B3LYP and HF methods with the basis set of $6-31 G(d)$. Thermodynamic parameters of the molecule are determined by means of vibration frequency analysis.

\section{RESULTS AND DISCUSSION}

The chemical structure of the title compound has been determined by X-ray analysis in our previous work. (Karakus et al., 2014). The molecular structure of the title compound is illustrated in Figure 1. A dithiophosphonate bridged methoxyphenyl and bis(trifluorophenylethyl) groups and a triethylammonium moiety connected by N-H...S and $\mathrm{C}-\mathrm{H}$...F hydrogen bonds are included in this compound, where the bond lengths between atoms in the molecules are higly compatible with standard values (Allen et al., 1987), and usually quite compatible with those in the formerly reported molecule. (Solak et al., 2011).

\section{Thermodynamic Analysis}

The temperature addiction of the thermodynamic parametrs such as heat capacity at constant pressure $\left(C_{p, m}^{0}\right)$, entropy $\left(S_{p, m}^{0}\right)$, enthalpy $\left(H_{p, m}^{0}\right)$, Gibbs's free energy $(\Delta G)$ and thermal energy $(E)$ for the compound are determined by both DFT/B3LYP/6-31G(d) and HF/6-31G(d) methods. The temperature dependence of them for the compound is listed in Table 1, Figure 2(a), (b), (c), (d) and (e), demonstrate the correlation of heat capacity at constant pressure $\left(C_{p, m}^{0}\right)$, entropy $\left(S_{p, m}^{0}\right)$, enthalpy $\left(H_{p, m}^{0}\right)$, Gibbs's free energy $(\Delta G)$ and thermal energy $(E)$, respectively, for the methods of DFT and HF levels. Table 1 reveals that the entropy, heat capacities, and enthalpy changes are increasing with temperature between $100 \mathrm{~K}$ and $700 \mathrm{~K}$ due to the fact that the intramolecular vibration intensities increases with temperature (Bellamy, 1964). The thermodynamics functions for the title compound as a function of temperatures by utilizing DFT/B3LYP and HF methods with 6-31G(d) levels are given as follows, 

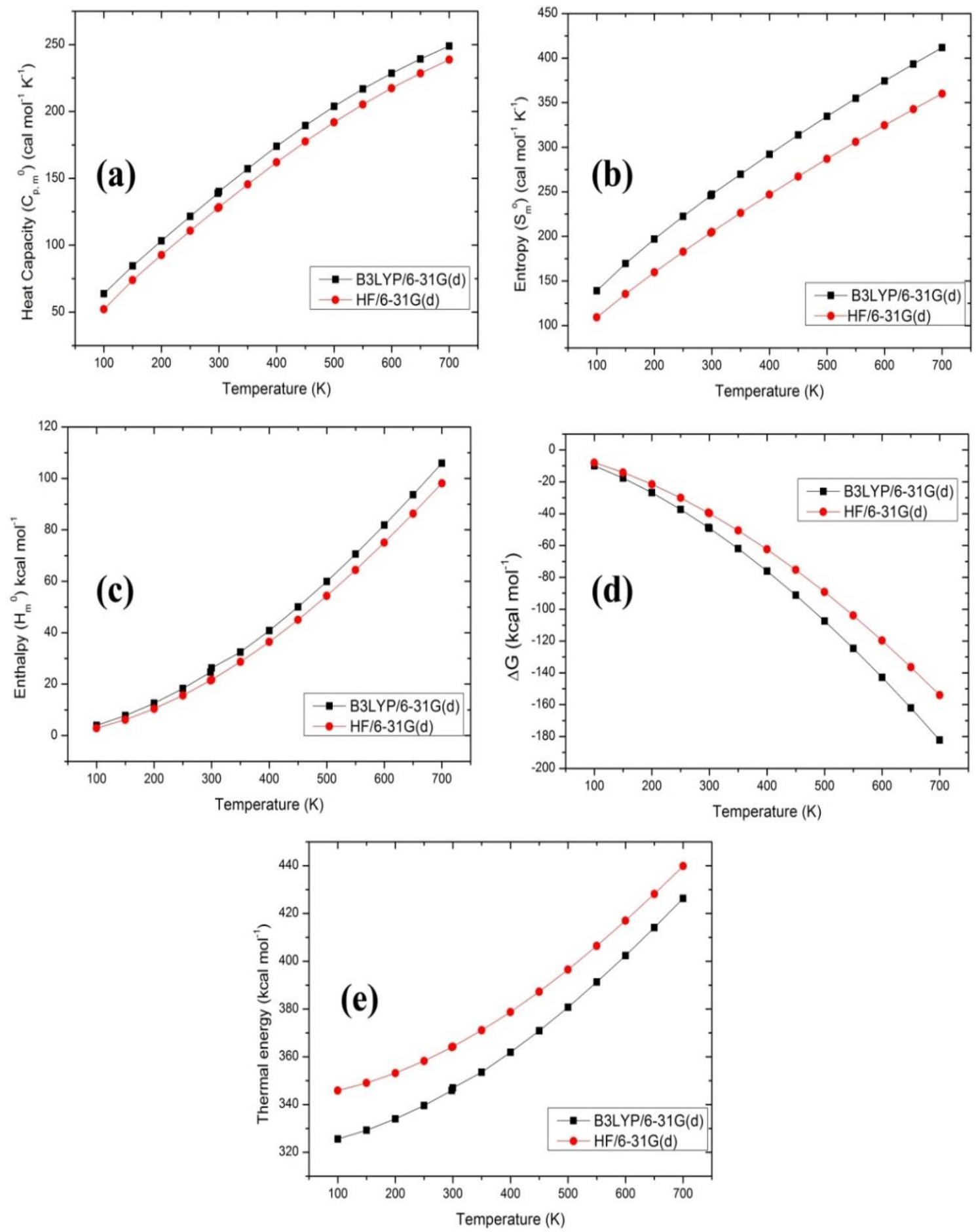

Figure 2. The correlation graphs between various temperature versus (a) Heat capacity, (b) Entropy, (c) Enthalpy, (d) Gibbs free energy and (e) Thermal energy of the title compound for B3LYP/6-31G(d) and HF/ 6$31 \mathrm{G}(\mathrm{d})$ levels. 
Table 1. Thermodynamic features at elevated temperatures with using DFT/B3LYP/6-31G(d) and HF/6-31G(d) levels, respectively.

\begin{tabular}{|c|c|c|c|c|c|c|c|c|c|c|}
\hline \multirow[b]{2}{*}{$\mathbf{T}(\mathbf{K})$} & \multicolumn{2}{|c|}{$\mathrm{C}\left(\mathrm{cal} \mathrm{mol}^{-1} \mathrm{~K}^{-1}\right)$} & \multicolumn{2}{|c|}{$S\left(\right.$ cal $\left.\mathrm{mol}^{-1} \mathrm{~K}^{-1}\right)$} & \multicolumn{2}{|c|}{$\Delta \mathbf{H}\left(\mathrm{kcal} \mathrm{mol}^{-1}\right)$} & \multicolumn{2}{|l|}{ Gibbs } & \multicolumn{2}{|c|}{ Total energy } \\
\hline & B3LYP & HF & B3LYP & HF & B3LYP & HF & B3LYP & HF & B3LYP & HF \\
\hline 100 & 63.78 & 52.08 & 138.94 & 109.29 & 3.97 & 2.91 & -9.92 & -8.02 & 325.54 & 345.84 \\
\hline 150 & 84.48 & 73.85 & 169.62 & 135.35 & 7.79 & 6.16 & -17.65 & -14.14 & 329.26 & 348.99 \\
\hline 200 & 103.24 & 92.68 & 197.04 & 159.73 & 12.59 & 10.42 & -26.83 & -21.52 & 333.96 & 353.15 \\
\hline 250 & 121.48 & 110.75 & 222.54 & 182.81 & 18.31 & 15.61 & -37.33 & -30.09 & 339.58 & 358.24 \\
\hline 298.15 & 138.91 & 127.72 & 245.78 & 204.13 & 24.67 & 21.45 & -48.61 & -39.41 & 345.85 & 363.98 \\
\hline 300 & 140.21 & 128.36 & 247.25 & 204.93 & 26.25 & 21.69 & -49.10 & -39.79 & 346.96 & 364.22 \\
\hline 350 & 157.21 & 145.53 & 269.81 & 226.32 & 32.45 & 28.64 & -61.98 & -50.57 & 353.53 & 371.07 \\
\hline 400 & 173.99 & 162.01 & 292.17 & 247.10 & 40.84 & 36.43 & -76.03 & -62.41 & 361.81 & 378.76 \\
\hline 450 & 189.58 & 177.55 & 313.81 & 267.33 & 50.03 & 45.02 & -91.18 & -75.27 & 370.91 & 387.26 \\
\hline 500 & 203.86 & 191.98 & 334.74 & 287.00 & 59.97 & 54.37 & -107.40 & -89.13 & 380.75 & 396.50 \\
\hline 550 & 216.83 & 205.27 & 354.98 & 306.12 & 70.60 & 64.40 & -124.65 & -103.96 & 391.27 & 406.44 \\
\hline 600 & 228.58 & 217.43 & 374.53 & 324.68 & 81.83 & 75.07 & -142.89 & -119.74 & 402.41 & 417.01 \\
\hline 650 & 239.22 & 228.56 & 393.42 & 342.69 & 93.63 & 86.33 & -162.09 & -136.42 & 414.11 & 428.16 \\
\hline 700 & 248.88 & 238.73 & 411.65 & 360.15 & 105.94 & 98.11 & -182.22 & -154.00 & 426.32 & 439.85 \\
\hline
\end{tabular}

$$
\begin{aligned}
& B 3 L Y P / \quad C_{p, m}^{0}=6.289+0.516 T-2.429 \times 10^{-4} T^{2} \quad\left(R^{2}=0.9998\right) \\
& H F / \quad C_{p, m}^{0}=8.519+0.456 T-1.799 \times 10^{-4} T^{2} \quad\left(R^{2}=0.9999\right)(2) \\
& B 3 L Y P / \quad S_{m}^{0}=83.381+0.599 T-1.880 \times 10^{-4} T^{2} \quad\left(R^{2}=0.9997\right) \quad(3) \\
& H F / \quad S_{m}^{0}=59.415+0.525 T-1.377 \times 10^{-4} T^{2} \quad\left(R^{2}=0.9999\right) \quad(4) \\
& B 3 L Y P / \quad H_{m}^{0}=-2.776+0.047 T+1.551 \times 10^{-4} T^{2} \quad\left(R^{2}=0.9998\right)(5) \\
& H F / \quad H_{m}^{0}=-2.613+0.035 T+1.157 \times 10^{-4} T^{2} \quad\left(R^{2}=0.9998\right) \quad(6) \\
& B 3 L Y P / \quad \Delta G=3.901-0.111 T-2.223 \times 10^{-4} T^{2} \quad\left(R^{2}=0.9998\right) \quad(7) \\
& H F / \Delta G=2.356+0.079 T-2.069 \times 10^{-4} T^{2} \quad\left(R^{2}=0.9999\right) \\
& B 3 L Y P / \quad E=319.029+0.0045+1.559 \times 10^{-4} T^{2} \quad\left(R^{2}=0.9998\right)(9) \\
& H F / \quad E=340.513+0.033 T+1.569 \times 10^{-4} T^{2} \quad\left(R^{2}=0.9998\right)(10)
\end{aligned}
$$


The regressions factors $\left(R^{2}\right)$ of these observed relations of the thermodynamic functions versus temperature are all not less than 0.999. For example, the regression values of the thermal energy for the methods of DFT and HF are found as 0.9998. These above equations are used to estimate the values of the any thermodynamic parameters for any

temperature. All the thermodynamics data obtained from theoric calculation supply beneficial predictions for further work on the molecule. These data can be used to calculate other thermodynamic energy parameters using the second law of thermodynamics (Zhang et al., 2010).

\section{Frontier molecular orbital analysis}

The molecular orbital (MO) is a considerable concept in chemistry and molecular orbital theory is widely used to describe chemical behavior. MO is used as a set of tools to explain chemical behavior, such as reactivity, kinetics and global and local chemical reactivity parameters (Nasiri et al., 2018). It also provides to construct the description of other phenomenon involving molecular electronic structure containing charge-transfer processes, photo excitation, magnetism and molecular electronics. The most important frontier molecular orbitals (FMOs) such as Lowest Unoccupied and Highest Occupied Molecular Orbital (LUMO-HOMO) are major role in determining the behavior of compounds at the molecular level (Kosar and Albayrak, 2011). At the same time, the difference between these HOMO and LUMO orbital energies is called energy gap. This energy gap is directly related to the chemical activity and stability of the molecule (Lewis et al., 1994). The HOMO and LUMO orbitals represent the ability of molecules to donate and acceptor electrons, respectively. (Tasli et al., 2015). The HOMO and LUMO molecular orbital energies are performed with using DFT/B3LYP and HF levels with the basis set of 6-31G(d) for the compound in this study. The dispersions, energy levels and 3D desing of the HOMO and LUMO orbitals for the material of the compound via DFT/B3LYP level is shown in Figure 3(a).

In this section, the global and local chemical reactivity parameters (Nasiri et al., 2018), which play an important role in understanding the reactivity of the molecule, were calculated by using HOMO and LUMO orbital energies. Thus, Frontier molecular orbital energies $(\mathrm{eV})$, Ionisation potential $\mathrm{I}(\mathrm{eV})$, electron affinity A (eV), global electronegativity $\chi(\mathrm{eV})$, total hardness $\eta(\mathrm{eV})$, global softness (S) and global electrophilicity $\omega(\mathrm{eV})$ of the compound are performed by using both B3LYP/6-31G(d) and HF/6-31G(d) levels, respectively. Also, they are listed in Table 2. As shown in Table 2, the energy differences between the HOMO and LUMO energy levels of the compound considered in this work for the methods of DFT and HF are found as $3.601 \mathrm{eV}$ and $9.981 \mathrm{eV}$, respectively. A molecule is known as soft if it has a low energy vacancy and is known as hard if it has a wide energy vacancy (Karabacak et al., 2014). The chemical hardness value is $5.087 \mathrm{eV}$ for. This molecule is harder than some similar molecules (Bayrakdar et al., 2015; Muthu et al., 2015). 
Table 2. FMOs molecular orbital energies $(\mathrm{eV})$, Ionization potential $\mathrm{I}(\mathrm{eV})$, electron affinity $\mathrm{A}(\mathrm{eV})$, global electronegativity $\chi(\mathrm{eV})$, total hardness $\square(\mathrm{eV})$, global softness $(\mathrm{S})$ and global electrophilicity $\omega(\mathrm{eV})$ of the title compound are calculated by using both DFT/B3LYP/6-31G(d) and HF/6-31G(d) levels, respectively.

\begin{tabular}{lcc}
\hline Parameters & B3LYP & HF \\
\hline $\boldsymbol{E}_{\text {LUMo }}(\boldsymbol{e V})$ & -1.425 & 2.507 \\
$\boldsymbol{E}_{\text {Hомо }}(\boldsymbol{e V})$ & -5.026 & -7.474 \\
$\Delta \boldsymbol{E}_{\text {HOMO-LUMO }}(\mathbf{e V})$ & 3.601 & 9.981 \\
$\mathbf{I}(\boldsymbol{e V})$ & 5.026 & 7.474 \\
$\mathbf{A}(\boldsymbol{e V})$ & 1.425 & -2.700 \\
$\chi(\boldsymbol{e V})$ & -3.226 & -2.387 \\
$\eta(\boldsymbol{e V})$ & 1.801 & 5.087 \\
$\mathbf{S}\left(\boldsymbol{e} \boldsymbol{V}^{-1}\right)$ & 0.278 & 0.098 \\
$\boldsymbol{\omega}(\boldsymbol{e V})$ & 9.369 & 15.388 \\
\hline
\end{tabular}

\section{Analysis of molecular electrostatic potential}

Molecular electrostatic potential map (MEP) is one of the powerful methods for determining the relative polarity of compounds (Reed;Weinhold, 1985). MEP diagrams are used to understand the reactivity of compounds, in that Negative sites on the map are considered nucleophilic centers, while positive sites are considered potential electrophilic centres (Chidangil et al., 1998). The molecular electrostatic potential (MEP) at any $\mathrm{R}$ point in the space around a molecule (in atomic units) can be calculated by the following formula;

$V(r)=\sum_{A} \frac{Z_{A}}{\left|\overrightarrow{R_{A}}-\vec{r}\right|}-\int \frac{\rho\left(\overrightarrow{r^{\prime}}\right)}{\left|\overrightarrow{r^{\prime}}-\vec{r}\right|} d^{3} r^{\prime}$,

in this equation, $Z_{A}$ is represent charge over the A nucleus localized in region at $R_{A}$ and $\rho\left(r^{\prime}\right)$ is represent the electronic density function of the molecule, also $r^{\prime}$ is expressed the imaginary integration variable. The potential contributions attributed to the nuclei and the electrons are expressed by the first and second terms, respectively.

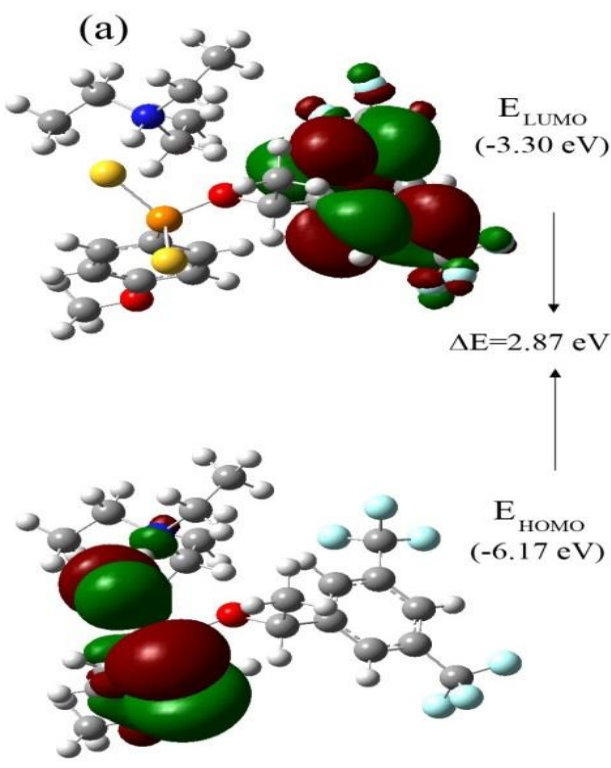

\section{(b)}

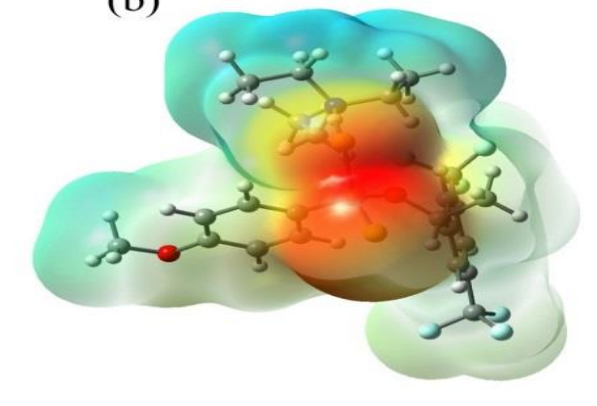

Figure 3. (a) 3D graphics of the frontier orbitals of compound, (b) The molecular electrostatic potential surface of title compound by using DFT/6-31G(d) level. 
The map of the MEP surface is much quite for explication of the nucleophilic and electrophilic reactions for the work of hydrogen bonding interactions and biological identification process (Koşar et al., 2010). MEP maps is consist of color codes, which this colors expressed by mapping electrostatic potential onto the total electron density. The blue colored regions on the map show positive potential values while the red colored regions show negative potential values. Also, green colored regions define zero potential surfaces. MEP maps for the title compound at the level of DFT/B3LYP/6-31G(d) is shown in Figure 3 (b). The MEP surfaces with red and blue colors indicate the high and lowest electron density, respectively. In addition, the electron density and MEP surfaces are quite successful methods in explaining hydrogen bonding interactions (Miertuš et al., 1981; Okulik;Jubert, 2005).

\section{CONCLUSION}

Electronic properties of the compound are presented for the first time by using DFT and HF calculations in this work. Computational chemistry methods are beneficial, fast and cheap tools used for identification structure of the chemical compounds. As a result, the results obtained this study can be summarized as follows;

1- The thermodynamic properties and the values of the HOMO-LUMO orbitals in the ground state of the compound are calculated by using DFT and HF methods which are theoretical calculation techniques.

2- Relations between statistical thermodynamics and temperature have been investigated. In Fig. 2(a), (b), (c) and (e), the heat capacity of the molecule, entropy, enthalpy and thermal energy increase with temperature, while in Fig. 2(d), Gibbs energy decreases with increasing temperature.
3- Frontier molecular orbital analysis shows that charge transfer takes place within the molecule. The charge density distribution and chemical reactivity of the compound were investigated via the MEP map. The MEP map has shown that the negative potential region is localized on electronegative atoms and positive potential regions are localized on hydrogen atoms.

\section{REFERENCES}

Alberti E, Ardizzoia G, Brenna S, Castelli F, Galli S, Maspero A, 2007. The synthesis of a new dithiophosphonic acid and its coordination properties toward Ni (II): A combined NMR and X-ray diffraction study. Polyhedron, 26(5): 958966.

Allen FH, Kennard O, Watson DG, Brammer L, Orpen AG, Taylor R, 1987. Tables of bond lengths determined by X-ray and neutron diffraction. Part 1. Bond lengths in organic compounds. Journal of the Chemical Society, Perkin Transactions 2, (12): S1-S19.

Aragoni MC, Arca M, Demartin F, Devillanova FA, Graiff C, Isaia F, Lippolis V, Tiripicchio A, Verani G, 2000. Ring-Opening of Lawesson's Reagent: New Syntheses of Phosphono-and Amidophosphono-Dithioato ComplexesStructural and CP-MAS 31P-NMR Characterization of [p-CH3OPh (X) PS2] 2M ( $\mathrm{X}=\mathrm{MeO}$, iPrNH; $\mathrm{M}=\mathrm{NiII}$, PdII, and PtII). European Journal of Inorganic Chemistry, 2000(10): 2239-2244.

Aragoni MC, Arca M, Demartin F, Devillanova FA, Graiff C, Isaia F, Lippolis V, Tiripicchio A, Verani G, 2001. Reactivity of phosphonodithioato Ni II complexes: solution equilibria, solid state studies and theoretical calculations on the adduct formation with some pyridine derivatives. Journal of the Chemical Society, Dalton Transactions, (18): 2671-2677.

ASIF M, 2018. REVIEW ON TO FREE RADICALS, ANTIOXIDANTS AND BRIEF OVERVIEW OF OXIMES. International Journal of Current Research in Applied Chemistry \& Chemical Engineering [ISSN: 2581-5385 (online)], 2(1). 
Aydemir C, Solak S, Acar Doganlı G, Sensoy T, Arar D, Bozbeyoglu N, Mercan Dogan N, Lönnecke P, Hey-Hawkins E, Sekerci M, 2015. Synthesis, Characterization, and Antibacterial Activity of Dithiophosphonates and Amidodithiophosphonates. Phosphorus, Sulfur, and Silicon and the Related Elements, 190(3): 300-309.

Bayrakdar A, Kart H, Elcin S, Deligoz H, Karabacak M, 2015. Synthesis and DFT calculation of a novel 5, 17-di (2-antracenylazo)-25, 27-di (ethoxycarbonylmethoxy)-26, 28-dihydroxycalix [4] arene. Spectrochimica Acta Part A: Molecular and Biomolecular Spectroscopy, 136: 607-617.

Bellamy LJ. 1964. The infra-red spectra of complex molecules.

Chermette H, 1998. Density functional theory: a powerful tool for theoretical studies in coordination chemistry. Coordination chemistry reviews, 178: 699-721.

Chidangil S, Shukla MK, Mishra PC, 1998. A molecular electrostatic potential mapping study of some fluoroquinolone anti-bacterial agents. Molecular modeling annual, 4(8): 250-258.

Corminboeuf C, Tran F, Weber J, 2006. The role of density functional theory in chemistry: Some historical landmarks and applications to zeolites. Journal of Molecular Structure: THEOCHEM, 762(1): 1-7.

Foresman J,Frish E, 1996. Exploring chemistry. Gaussian Inc., Pittsburg, USA.

Frisch M, Trucks G, Schlegel H, Scuseria G, Robb M, Cheeseman J, Scalmani G, Barone V, Mennucci B, Petersson G, 2009. Gaussian 09, rev. D. 01. Gaussian Inc., Wallingford CT.

Gataulina AR, Safin DA, Gimadiev TR, Pinus MV, 2008. Complexes of podand-containing bis (dithiophosphonate) ligands with cobalt (II), nickel (II) and cadmium (II): recognition of $\mathrm{CH} 2 \mathrm{Cl}$ 2. Transition Metal Chemistry, 33(7): 921.

Gray IP, Milton HL, Slawin AM, Woollins JD, 2003. Synthesis and structure of [Fc (RO) PS 2]complexes. Dalton Transactions, (17): 34503457.

Gray IP, Slawin AM, Woollins JD, 2004. Synthesis and structure of [An (RO) PS 2]- complexes. Dalton Transactions, (16): 2477-2486.
Karabacak M, Asiri A, Al-Youbi A, Qusti A, Cinar M, 2014. Identification of structural and spectral features of synthesized cyano-stilbene dye derivatives: A comparative experimental and DFT study. Spectrochimica Acta Part A: Molecular and Biomolecular Spectroscopy, 120: 144-150.

Karabacak M, Çoruh A, Kurt M, 2008. FT-IR, FTRaman, NMR spectra, and molecular structure investigation of 2, 3-dibromo-Nmethylmaleimide: A combined experimental and theoretical study. Journal of Molecular Structure, 892(1): 125-131.

Karakus M, 2011. Synthesis and Characterization of Chiral Gold (I) Phosphine Complexes with New Dithiophosphorus Ligands. Phosphorus, Sulfur, and Silicon and the Related Elements, 186(7): 1523-1530.

Karakus M, Kara I, Çelik Ö, Orujalipoor I, İde S, Yilmaz H, 2018. Synthesis, characterization, single crystal structure and theoretical studies of trans-Ni (II)-complex with dithiophosphonate ligand. Journal of Molecular Structure, 1163: 128-136.

Karakus M, Lönnecke P, Hey-Hawkins E, 2004. Zwitterionic ferrocenyldithiophosphonates: the molecular structure of $[\mathrm{FcP}(\mathrm{S}) \mathrm{S}(\mathrm{OCH} 2 \mathrm{CH} 2$ $\mathrm{NH} 2 \mathrm{Me})][\mathrm{Fc}=\mathrm{Fe}(\eta 5-\mathrm{C} 5 \mathrm{H} 4)(\eta$ 5-C $5 \mathrm{H} 5)]$. Polyhedron, 23(14): 2281-2284.

Karakus M, Lönnecke P, Hildebrand M, Hey-Hawkins E, 2011. Chiral Heterobimetallic Gold (I) Ferrocenyldithiophosphonato Complexes. Zeitschrift für anorganische und allgemeine Chemie, 637(7-8): 983-987.

Karakus M, Solak S, Hökelek T, Dal H, Bayrakdar A, Kart SÖ, Karabacak M, Kart H, 2014. Synthesis, crystal structure and ab initio/DFT calculations of a derivative of dithiophosphonates. Spectrochimica Acta Part A: Molecular and Biomolecular Spectroscopy, 122: 582-590.

Kosar B,Albayrak C, 2011. Spectroscopic investigations and quantum chemical computational study of (E)-4-methoxy-2-[(ptolylimino) methyl] phenol. Spectrochimica Acta Part A: Molecular and Biomolecular Spectroscopy, 78(1): 160-167. 
Koşar B, Albayrak Ç, Odabaşoğlu M, Büyükgüngör O, 2010. (E)-3-[(3-(Trifluoromethyl) phenylimino) methyl] benzene-1, 2-diol: X-ray and DFT calculated structures. Turkish Journal of Chemistry, 34(3): 481-487.

Liu S-L, Wang X-Y, Duan T, Leung W-H, Zhang Q-F, 2010. Hydrolysis and coordination behavior of ferrocenyl-phosphonodithiolate: Synthesis and structure of $\mathrm{Cu} 4[\mathrm{FcP}(\mathrm{OCH} 3)(\mu-\mathrm{S})(\mu 3-\mathrm{S})] 4$ $[\mathrm{Fc}=\mathrm{Fe}(\eta 5-\mathrm{C} 5 \mathrm{H} \mathrm{4})(\eta$ 5-C $5 \mathrm{H} \mathrm{5})]$. Journal of molecular structure, 964(1): 78-81.

Maspero A, Kani I, Mohamed AA, Omary MA, Staples RJ, Fackler JP, 2003. Syntheses and structures of dinuclear gold (I) dithiophosphonate complexes and the reaction of the dithiophosphonate complexes with phosphines: Diverse coordination types. Inorganic chemistry, 42(17): 5311-5319.

Miertuš S, Scrocco E, Tomasi J, 1981. Electrostatic interaction of a solute with a continuum. A direct utilizaion of $\mathrm{AB}$ initio molecular potentials for the prevision of solvent effects. Chemical Physics, 55(1): 117-129.

Muthu S, Porchelvi EE, Karabacak M, Asiri A, Swathi SS, 2015. Synthesis, structure, spectroscopic studies (FT-IR, FT-Raman and UV), normal coordinate, NBO and NLO analysis of salicylaldehyde

chlorophenylthiosemicarbazone. Journal of Molecular Structure, 1081: 400-412.

Nasiri SK, Reisi-Vanani A, Hamadanian M, 2018. Molecular Structure, Spectroscopic, Local and Global Reactivity Descriptors and NBO Analysis of C32H12: A New Buckybowl and SubFullerene Structure. Polycyclic Aromatic Compounds: 1-12.

Okulik N,Jubert AH, 2005. Theoretical analysis of the reactive sites of non-steroidal anti-inflammatory drugs. Internet Electronic Journal of Molecular Design, 4(1): 17-30.

Reed AE,Weinhold F, 1985. Natural localized molecular orbitals. The Journal of chemical physics, 83(4): 1736-1740.

Solak S, 2011. Ditiyofosfor Bileşiklerinin Sentezi, Mono ve Dinükleer Altın(I) ve Gümüş(I) Kompleklerinin Araştırılması, Pamukkale Üniversitesi Yüksek Lisans Tezi(Basılmış).
Solak S, Karakuş M, Tercan B, Hökelek T, 2011. Triethylammonium (S)-(-)-O-[1-(2-naphthyl) ethyl](4-methoxyphenyl) dithiophosphonate. Acta Crystallographica Section E: Structure Reports Online, 67(5): o1260-o1261.

Sundaraganesan N, Anand B, Meganathan C, Joshua BD, 2008a. FT-IR, FT-Raman spectra and ab initio HF, DFT vibrational analysis of $\mathrm{p}$ chlorobenzoic acid. Spectrochimica Acta Part A: Molecular and Biomolecular Spectroscopy, 69(3): 871-879.

Sundaraganesan N, Meganathan C, Joshua BD, Mani P, Jayaprakash A, 2008b. Molecular structure and vibrational spectra of 3-chloro-4-fluoro benzonitrile by $\mathrm{ab}$ initio $\mathrm{HF}$ and density functional method. Spectrochimica Acta Part A: Molecular and Biomolecular Spectroscopy, 71(3): 1134-1139.

Şener N, Bayrakdar A, Kart HH, Şener I, 2017. A combined experimental and DFT investigation of disazo dye having pyrazole skeleton. Journal of Molecular Structure, 1129: 222-230.

Taslı P, Bayrakdar A, Karakus O, Kart H, Koc Y, 2015. Synthesis and characterization of three novel Schiff base compounds: Experimental and theoretical study. Optics and Spectroscopy, 119(3): 467-484.

Thomas CM, Neels A, Stœckli-Evans H, Süss-Fink G, 2001. Synthesis and structure of $[(\mathrm{C} 5 \mathrm{H} 5) \mathrm{Fe}(\mathrm{C}$ $5 \mathrm{H} 4$ PS 2 OCH 2 C 6 H 4 N 3)]-, a new phosphonodithioate derivative, and its coordination chemistry with rhodium (I) and nickel (II). Journal of Organometallic Chemistry, 633(1): 85-90.

van Zyl WE, López-de-Luzuriaga JM, Mohamed AA, Staples RJ, Fackler JP, 2002. Dinuclear Gold (I) Dithiophosphonate Complexes: Synthesis, Luminescent Properties, and X-ray Crystal Structures of [AuS2PR (OR ')] $2(\mathrm{R}=\mathrm{Ph}, \mathrm{R}$ '= C5H9; R= 4-C6H4OMe, R '=(1 S, 5 R, 2 S $)-(-)$ Menthyl; $\left.\mathrm{R}=\mathrm{Fc}, \mathrm{R}{ }^{\prime}=(\mathrm{CH} 2) 2 \mathrm{O}(\mathrm{CH} 2) 2 \mathrm{OMe}\right)$. Inorganic chemistry, 41(17): 4579-4589.

Zhang R, Du B, Sun G, Sun Y, 2010. Experimental and theoretical studies on $\mathrm{o}-, \quad \mathrm{m}$-and $\mathrm{p}$ chlorobenzylideneaminoantipyrines.

Spectrochimica Acta Part A: Molecular and Biomolecular Spectroscopy, 75(3): 1115-1124. 